\title{
Eco-Epidemiology of Cutaneous Leishmaniasis in Golestan Province, Northeastern Iran: A Systematic Review
}

\author{
Omid Mozafari ${ }^{1}$, Aioub Sofizadeh ${ }^{2 *}$, Hamid Reza Shoraka $^{3}$, Javad Namroodi $^{4}$, Ehsan Allah Kalteh $^{5}$ \\ 1. Health Management and Social Development Research Center, Golestan University of Medical Sciences, Gorgan, \\ Iran \\ 2. Infectious Disease Research Center, Golestan University of Medical Sciences, Gorgan, Iran \\ 3. Vector-borne Diseases Research Center, North Khorasan University of Medical Sciences, Bojnurd, Iran \\ 4. Kalaleh Health Center, Golestan University of Medical Sciences, Gorgan, Iran. \\ 5. Management and Social Development Research Center, Golestan University of Medical Sciences, Gorgan, Iran
}

\section{Article Type:}

Systematic Review

\section{Article History:}

Received: 3 Jan 2020

Revised: 25 Feb 2020

Accepted: 29 Mar 2020

\section{*Correspondence:}

Aioub Sofizadeh, Infectious Disease Research Center, Golestan University of Medical Sciences, Gorgan, Iran A_sofizadeh@yahoo.com

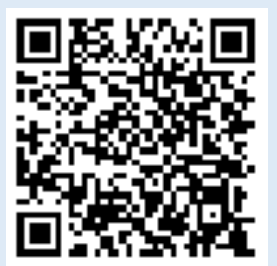

DOI: 10.29252/jorjanibiomedj.8.1.60

\begin{abstract}
Background and objective: zoonotic cutaneous leishmaniasis (ZCL) is one of the most important health problems in Golestan Province, northeastern Iran. Several studies have investigated various aspects of the disease in this province. Herein, we provide a detailed review of the results of all studies related to leishmaniasis to give a reliable insight into the state of the disease in this province.
\end{abstract}

Methods: The search for articles was performed in PubMed, Scopus, and Web of Science without language restriction until the beginning of 2019. Articles in Persian were retrieved from the Magiran, Scientific Information Database, and IranMedex. Overall, 41 articles were subjected to content analysis under the different themes.

Results: Counties of Gonbad-e-Kavus and Maraveh Tappeh are endemic areas of ZCL with an incidence rate 99.4-379.1 in 100000 population and has mesoendemic situation in these counties. Leishmania major is the dominant (99.1\%) agent of leishmaniasis. Among 18 sandflies species detected in the province, Phlebotomus papatasi was the main vector of the disease with a mean infection rate of $9.2 \%$. Peak of sandflies activity was recorded in the mid-July and mid-September. Rhombomys opimus and Meriones libycus were the main reservoirs of this disease with a mean infection rate of 25.3 and $31.8 \%$. The density of sandflies and wild rodents were highest in the endemic areas for ZCL.

Conclusion: In Golestan Province, ZCL has been in a hypoendemic situation and in some areas in a mesoendemic situation and has increased significantly in recent years, so it is recommended to investigate the reasons for this increase.

Keywords: cutaneous leishmaniasis, sand fly, wild rodents, Golestan

Copyright $\subseteq$ 2018, Jorjani Biomedicine Journal has published this work as an open access article under the terms of the Creative Commons Attribution License (http://creativecommons.org/licenses/by-nc/4.0/) which permits noncommercial uses of the work while it is properly cited. 


\section{Introduction}

Cutaneous leishmaniasis (CL) is an important vector-borne disease that is transmitted to humans and animals by the bite of infected female sandflies, this disease causes skin lesions, mainly ulcers, on exposed parts of the body such as face, legs and hands and treated with current anti-leishmanial drugs such as sodium stibogluconate (Pentostam), meglumine antimoniate (Glucantime), miltefosine, pentamidine isethionate, amphotericin B, and heat therapy or cryotherapy $(1,2)$. The disease usually occurs in two main forms: zoonotic cutaneous leishmaniasis (ZCL) and anthroponotic cutaneous leishmaniasis (ACL). More than one million new cases of CL are reported annually in worldwide but the real figures are 6 to 10 -folds. About $90 \%$ of all cases of CL occur in Afghanistan, Algeria, Brazil, Iran, Peru, Saudi Arabia, and Syria (3-6). ZCL and ACL are the most common forms of cutaneous leishmaniasis in Iran. Each year, more than 22,000 new cases of cutaneous leishmaniasis are reported in Iran, that $80 \%$ of which are ZCL (7). ZCL is endemic in rural areas of 17 out of 31 provinces of Iran (8). In these areas, Leishmania major is the causative agent, while Phlebotomus papatasi and wild rodents such as Rhombomys opimus and Meriones libycus are known as the vector and reservoir hosts, respectively (8).

Golestan Province is one of the most important hotspots of leishmaniasis in Iran. $\mathrm{ZCL}$ is endemic in this province, especially in its northeastern areas. Therefore, many studies have been conducted on various aspects of the disease in this province. Collecting the results of these studies could help clarify the features of this disease and contribute to decision-making for prevention, diagnosis, control, and treatment of leishmaniasis in this area. Therefore, we aimed to provide a detailed review of the results of all studies related to leishmaniasis to give a reliable insight into the state of the disease in this province.

\section{Materials and Methods}

\section{Study area}

The Golestan Province $\left(53^{\circ} 57^{\prime}-5^{\circ} 23^{\prime}\right.$ E, $36^{\circ} 30^{\prime}-38^{\circ} 08^{\prime} \mathrm{N}$ ) is located in the northeast of Iran, bordering the Caspian Sea and Turkmenistan. The province has a dry and semi-arid climate in the north and northeastern parts, a temperate climate in the central parts and a mountainous and cold climate in the southern parts. The province has an area of $20437.74 \mathrm{Km}^{2}$ and comprises 14 counties.

\section{Search strategy}

This review includes results of all published studies until the beginning of 2019 that have been conducted on Cutaneous Leishmaniasis in the Golestan Province.

First, the following search terms were used for finding relevant articles in the Golestan Province: Golestan, Gonbad-e Kavus, Maraveh Tappeh, Turkmen Sahra, Leishmaniasis, Leishmania and sand fly. Since some of the words may have different spelling, the following search syntax was used: (Leishmania OR Sand*fl*) AND (Golestan OR Turkemen* OR Gonbad* or Maraveh*).

The search was performed in PubMed, Scopus, and Web of Science without any language restriction until the beginning of 2019. Articles in Persian were retrieved from the Magiran, Scientific Information Database, and IranMedex. In addition, the "Iranian Journal of Parasitology" was investigated as a 
key journal. Reference lists of the retrieved articles were also hand-searched. Finally, we contacted local experts and active researchers in the field of leishmaniasis to avoid missing any relevant articles.

\section{Selection of articles}

Articles on Leishmania type, prevalence (in humans), vectors, and reservoirs in the Golestan Province were included in the study. Studies that have been conducted in the whole country or in several provinces were included only if they had reported data related to the Golestan Province separately and clearly. After removing excluding duplicate articles by EndNote software and those that did not meet the inclusion criteria, 41 articles were subjected to content analysis under the following themes: 1. Epidemiology of leishmaniasis (distribution, incidence in counties of the province, prevalence of acute ulcer and scar in different age groups, and status of endemicity); 2. Ecology of vectors (fauna, monthly activity and its correlation with climate and geographical conditions); 3. Ecology of reservoirs (fauna, distribution and effect of climate and geographical conditions on distribution of rodents); 4. Relationship between the distribution of disease and distribution of sand flies and wild rodents; 5. Treatment of the disease (Fig. 1).

198 records identified through (SID,

Magiran, IranMedex and references of included articles)

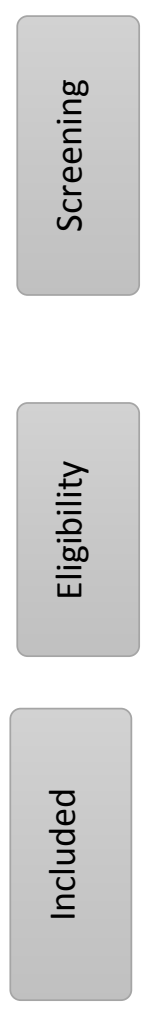

233 records identified through search in PubMed, Scopus and Web of Science

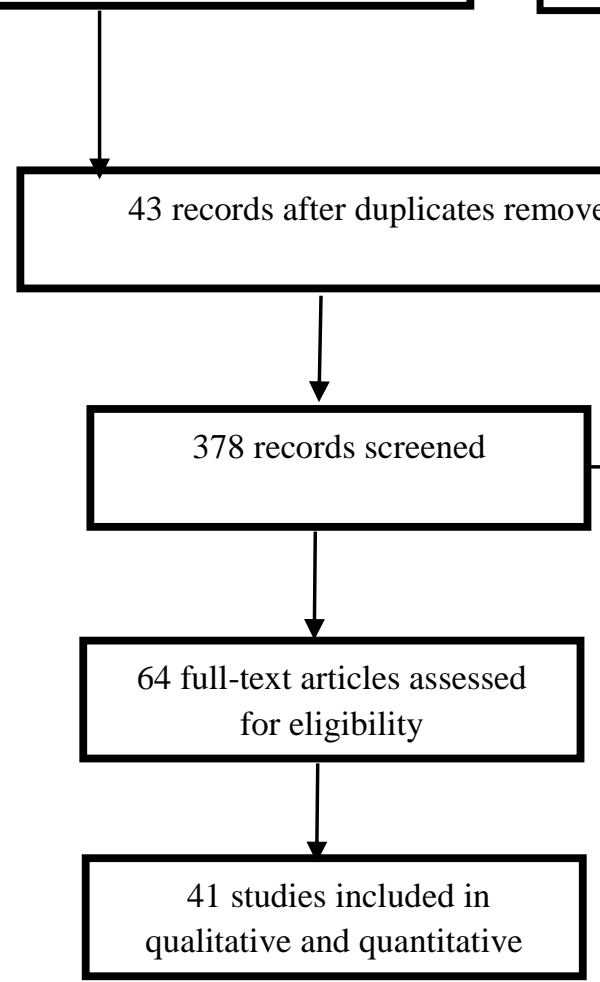

314 records excluded after title and abstract screening by inclusion criteria, described in methods

Fig 1. Flowchart describing the study design process 


\section{Data extraction}

Two researcher (A.S. and H.R.SH) extracted the Ecological characteristics of sand flies, Number of positive case. Author name and reviewed year. They evaluated the selected articles independently by reading titles, abstracts, and if necessary full texts. Any disagreements between the 2 researchers were solved by consultation of another reviewer.

Plotting maps: Using results of the published articles about Golestan Province, as well as unpublished information available in Golestan Province health center, the maps of cutaneous leishmaniasis distribution and incidence, distribution of sand flies and villages where have undergone rodenticide operations to reduce cutaneous leishmaniasis cases, have been drown.

\section{Results}

\section{The selected studies}

After a comprehensive search, 233 records identified through search in PubMed, Scopus and Web of Science and 198 records identified through SID, Magiran, IranMedex and references of included articles, 43 duplicates were removed. The relevance of the remaining 378 studies was evaluated based on the titles/ abstracts alone; of them, 64 studies were subjected to full-text review, which eliminated another 23 studies according to the inclusion and exclusion criteria. Finally, 41 studies were included in the present systematic review (Fig. $1)$.

\section{Epidemiology of leishmaniasis}

Leishmania species circulating in the Golestan Province

L. major was the predominant $(99.1 \%)$ species circulating in the province, and is endemic to this region; L. tropica was the least prevalent $(0.7 \%)$ species. Patients infected with L. tropica had a history of traveling to ACL endemic areas (9-18). One study also found L. turanica in $0.2 \%$ of patients (16).

\section{Incidence, prevalence, and distribution of leishmaniasis}

In the province, the most common form of leishmaniasis is ZCL with an annual incidence 31.7 per 100000 population. The disease is not uniformly distributed throughout the province; most cases were reported from counties of Gonbad-e Kavus and Maraveh Tappeh. The incidence rate in these endemic areas was 99.4 to 379.1 per 100,000 people between 2010 and 2016. The most important hotspots with the highest incidence rates were the districted of Karand and Atrak from the Gonbad-e Kavus County and the central districts from the Maraveh Tappeh County. In other counties, the incidence of leishmaniasis was between 3.8 and 28.7 per 100,000 people in 2016 , and most of the affected individuals in these counties had a history of traveling to endemic areas in the province or neighboring provinces. According to studies, about $68.4 \%$ of the affected population had cutaneous leishmaniasis scars. However, cutaneous leishmaniasis scars were present in all affected individuals in some villages (Tab. 1 and Fig. 2,3) (9-16, 19-20) 
Tab 1: incidence of cutaneous leishmaniasis in different counties of Golestan Province, 2006-2016.

\begin{tabular}{|c|c|c|c|c|c|c|}
\hline Author(s) & $\begin{array}{c}\text { Published } \\
\text { year }\end{array}$ & $\begin{array}{c}\text { Reviewed } \\
\text { year }\end{array}$ & Counties & $\begin{array}{c}\text { Num. } \\
\text { Positive } \\
\text { cases }\end{array}$ & $\begin{array}{c}\text { Incidence } \\
(\mathbf{1} / \mathbf{1 0 0 0 0 0})\end{array}$ & $\begin{array}{c}\text { Mean of } \\
\text { Incidence } \\
(\mathbf{1 / 1 0 0 0 0 0 )}\end{array}$ \\
\hline \multirow{5}{*}{ Cherabin et al. } & \multirow{5}{*}{2012} & 2006 & \multirow{7}{*}{$\begin{array}{c}\text { Maraveh } \\
\text { Tapeh }\end{array}$} & 1 & 1.8 & \multirow{7}{*}{117} \\
\hline & & 2007 & & 17 & 32 & \\
\hline & & 2008 & & 14 & 26 & \\
\hline & & 2009 & & 104 & 196 & \\
\hline & & 2010 & & 161 & 303 & \\
\hline Sofizadeh et al. & 2015 & 2012 & & 75 & 138.4 & \\
\hline Sofizadeh et al. & 2016 & 2013 & & 69 & $121 / 5$ & \\
\hline \multirow{4}{*}{ Sofizadeh et al. } & \multirow{4}{*}{2013} & 2007 & \multirow{5}{*}{$\begin{array}{c}\text { Gonbad-e } \\
\text { Kavus }\end{array}$} & - & 37.3 & \multirow{5}{*}{153} \\
\hline & & 2008 & & - & 48.9 & \\
\hline & & 2009 & & - & 199.9 & \\
\hline & & 2010 & & - & 379.11 & \\
\hline Sofizadeh et al. & 2016 & 2013 & & 334 & $99 / 4$ & \\
\hline \multirow{9}{*}{ Sofizadeh et al. } & \multirow{9}{*}{2016} & \multirow{9}{*}{2013} & Aghghala & 37 & $28 / 7$ & $28 / 7$ \\
\hline & & & Ramiyan & 24 & $27 / 3$ & $27 / 3$ \\
\hline & & & Gamishan & 9 & 14 & 14 \\
\hline & & & $\begin{array}{c}\text { Aliabad-e } \\
\text { katool } \\
\end{array}$ & 18 & $12 / 8$ & $12 / 8$ \\
\hline & & & Azadshahr & 10 & $10 / 1$ & $10 / 1$ \\
\hline & & & Gorgan & 39 & $8 / 7$ & $8 / 7$ \\
\hline & & & Kalaleh & 10 & $8 / 5$ & $8 / 5$ \\
\hline & & & Kordkooy & 5 & $6 / 9$ & $6 / 9$ \\
\hline & & & Bandar-e Gaz & 2 & $3 / 8$ & $3 / 8$ \\
\hline Sofizadeh et al. & 2016 & 2013 & $\begin{array}{l}\text { Golestan } \\
\text { Province }\end{array}$ & 573 & $31 / 7$ & $31 / 7$ \\
\hline
\end{tabular}



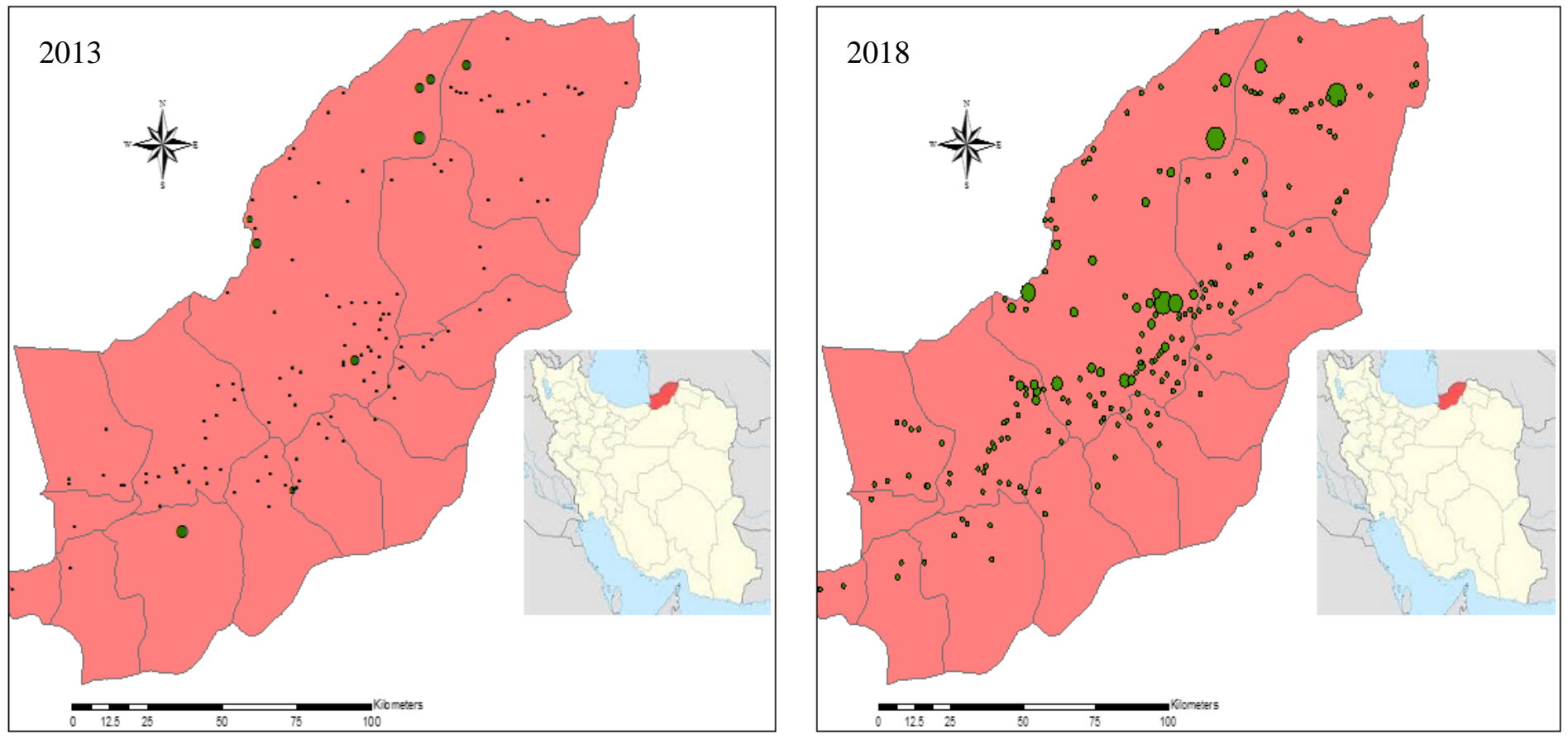

Fig 2: Number of cutaneous leishmaniasis cases in different villages of Golestan Province during 2013-2018 Each green circle represents a village, and the larger circles show the greater number of cutaneous leishmaniasis cases.

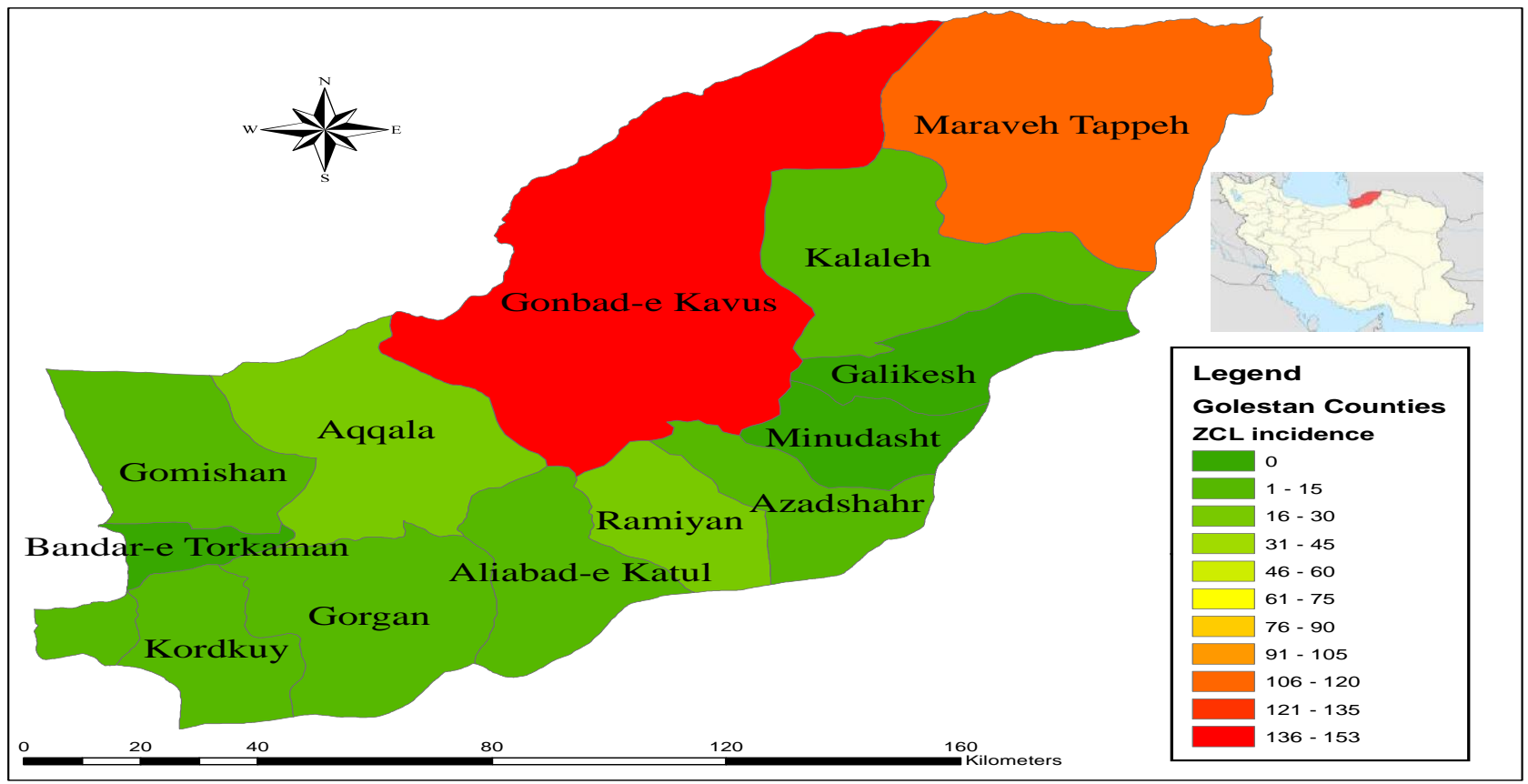

Fig. 3: mean incidence of cutaneous leishmaniasis reported in different counties of Golestan Province, 20062019 


\section{Temporal incidence of the disease}

Various studies in the province have shown that the incidence of leishmaniasis is more likely during November and December. This could indicate that the affected individuals might have been bitten during summer (the peak of sand flies activity) and later show clinical symptoms of illness after the incubation period $(9,21,22)$.

\section{Endemicity of ZCL in Golestan Province}

In five studies conducted in the province, approximately $55.5 \%$ of the examined population with acute ulcers was above 14 years of age. Thus, it can be inferred that the disease is hypo endemic in the province, but in some villages, majority of the affected individuals were under the age of 5 years, whilst the percentage of people under 14 years of age with acute ulcer had increased. Therefore, it can be stated that the disease is mesoendemic in some areas of the province $(9,19,21-23)$.

\section{Ecology of vectors}

Fauna and monthly activity of sand flies

Of 18 sand fly species identified in the province, 10 species were from Phlebotomus genus and eight were from Sergentomyia (Tab. 2) (20, 24-28).

The monthly activity of sand flies differed between arid/semi-arid areas and the southern foothill areas of the province. In the northern areas, especially in counties of Gonbad-e Kavus and Maraveh Tappeh, sand flies activity began in April and lasted until October. In these areas, the peak activity was recorded in mid-July and mid-September (20$21,26-27)$. In the southern areas, sand fly activity is shorter and lasts from June to October, and reaches its peak during September (Fig. 4 and Tab. 3) (20, 28). Sand flies are inactive during the day and become active from sunset until sunrise, but the peak activity is at $19-20 \mathrm{pm}$ (26).

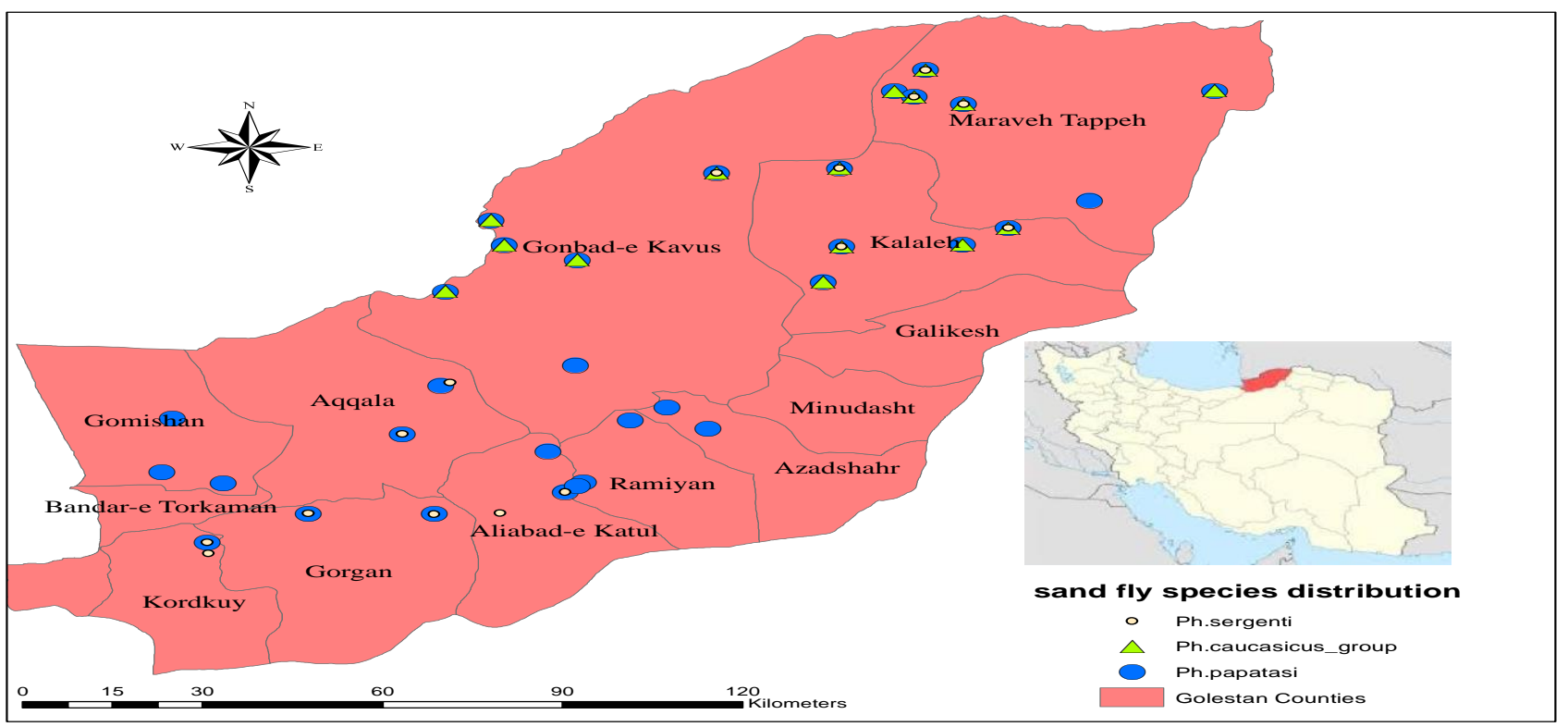

Fig 4. Distribution of important species of sand flies in different counties of Golestan Province 


\section{Density of sand flies}

Sand flies are more abundant in the northeastern areas of the province, which has an arid/semi-arid climate; however, they are less abundant in the western and southern areas of the province (20). The distribution of sand flies is directly correlated with endemic areas of cutaneous leishmaniasis, so that in north and northeast of the province that leishmaniasis is more prevalent, the frequency of sand flies also is more than other areas (20, 29). The sand flies were commonly found in rodent's burrows and birds' nests, outdoor places, and livestock barns and rarely found in human settlements (24).

Ph. papatasi and Sergentomyia sintoni are the predominant species in the Golestan Province (20, 24-29). Ph. papatasi is the main vector of cutaneous leishmaniasis in the province, the rate of L. major infection in this species was ranging between 0.3 and $13.5 \%$ (average 9.2\%). In addition, $P h$. papatasi infection with L. turanica and Leishmania closed gerbili was reported in some studies $(16,25$, 30-32).

Phlebotomus caucasicus and phlebotomus mongolensis as well as the female form of these species (known as the Ph. caucasicus group) have been reported in most studies in the Golestan Province. They are more abundant in the northeastern and eastern areas of the province (20). Infection of these species with L. major, $L$. turanica and $L$. closed gerbili has been reported, and the highest infection rates were related to $\mathrm{L}$. major (18.4\%) and L. closed gerbili (25\%), which is of great importance $(17,31,32)$. In Iran, these species are known as the zoonotic cycle vectors of L. major among rodents and the secondary vectors to humans. Therefore, the role of these species in the spread of cutaneous leishmaniasis and stability of parasites in this region is irrefutable $(7-8,33)$.

Although Phlebotomus sergenti is regarded as a vector for ACL in Iran (8), there has been no report of $P h$. sergenti infection with $\mathrm{L}$. tropica in the Golestan Province. This sand fly is a mountainous species and has a high prevalence in the province. It is found in arid and semi-arid parts of the province, such as Gonbad-e Kavus and Maraveh Tappeh, as well as in temperate foothill areas, such as Aliabad-e-Katul. Nevertheless, it is more abundant in the eastern and northeastern areas of the province, especially in the foothills of the aforementioned cities and less abundant in low-altitude areas (20- 21, 26-28).

Phlebotomus alexandri and Phlebotomus adlerius (sp) have also been reported in the province. These species are known as probable and primary vectors of Leishmania infantum in different parts of the world (34, 35). These two species had a limited distribution in the Golestan Province but were more prevalent in the foothill areas of Maraveh Tappeh, which is endemic for visceral leishmaniasis (20). In the city of Gonbad-e Kavus, L. (Saurolejshmaini) gymnodactyli has been detected in S. sintoni, a known vector of lizard Sauroleishmania (36). 
Tab 2: distribution of different species of sandflies in Golestan Province.

\begin{tabular}{|c|c|c|c|c|c|c|c|c|c|c|c|c|c|c|c|c|c|c|c|c|c|c|}
\hline 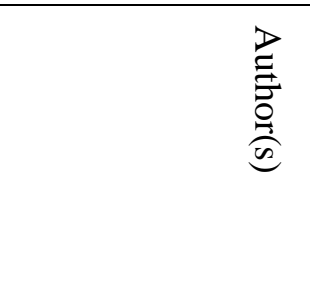 & 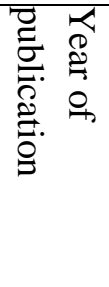 & $\underset{\stackrel{8}{\Xi}}{\stackrel{8}{E}}$ & 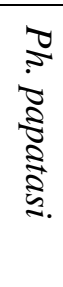 & 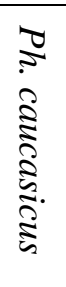 & $\begin{array}{l}\infty \\
\vdots \\
\Xi \\
5\end{array}$ & 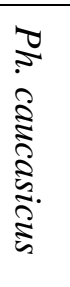 & 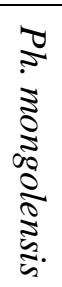 & 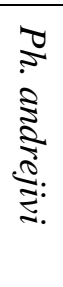 & 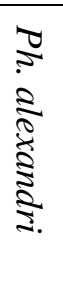 & 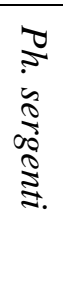 & 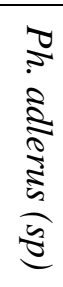 & $\begin{array}{l}\text { i. } \\
0 \\
0 \\
0 \\
0 \\
0\end{array}$ & 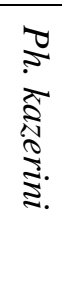 & 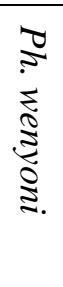 & $\begin{array}{l}y \\
y \\
\vdots \\
\vdots \\
\vdots\end{array}$ & 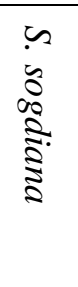 & 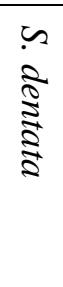 & 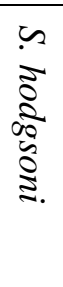 & 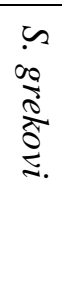 & $\begin{array}{l}0 \\
\stackrel{2}{2} \\
\frac{1}{2} \\
2\end{array}$ & 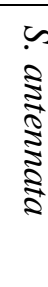 & 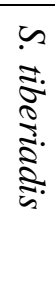 \\
\hline Parvizi et al. & 1998 & Gonbad-e Kavus & $*$ & - & - & - & $*$ & - & - & - & - & - & - & - & $*$ & - & - & - & - & - & - & - \\
\hline Rassi et al. & 2008 & Maraveh Tapeh & $*$ & $*$ & * & * & $*$ & $*$ & - & $*$ & $*$ & $*$ & $*$ & - & $*$ & $*$ & - & - & - & $*$ & - & - \\
\hline Sofizadeh et al. & 2014 & Aliabad-e Katul & $*$ & - & & - & - & - & - & $*$ & $*$ & $*$ & - & - & $*$ & - & $*$ & $*$ & - & - & - & - \\
\hline Sofizadeh et al. & 2015 & Maraveh Tapeh & $*$ & $*$ & * & * & $*$ & - & - & - & - & - & - & - & $*$ & - & - & - & - & * & - & - \\
\hline Agh-Atabay et al. & 2016 & Gonbad-e Kavus & $*$ & $*$ & & $*$ & $*$ & - & - & $*$ & - & $*$ & $*$ & - & $*$ & - & - & $*$ & $*$ & $*$ & $*$ & - \\
\hline \multirow[t]{8}{*}{ Sofizadeh et al. } & 2018 & Gonbad-e Kavus & $*$ & $*$ & & $*$ & $*$ & - & - & $*$ & - & $*$ & $*$ & - & $*$ & - & - & $*$ & $*$ & $*$ & $*$ & * \\
\hline & & Kalaleh & $*$ & $*$ & * & $*$ & $*$ & $*$ & - & $*$ & - & $*$ & $*$ & - & $*$ & - & - & - & $*$ & * & - & - \\
\hline & & Kordkuy & $*$ & - & & - & - & - & - & $*$ & - & - & - & - & $*$ & - & - & $*$ & - & - & - & - \\
\hline & & Bandar-e Gaz & - & - & & - & - & - & - & - & - & - & - & - & - & - & - & - & - & - & - & - \\
\hline & & Gorgan & $*$ & - & - & - & - & - & - & $*$ & & $*$ & - & - & $*$ & - & - & - & - & - & - & - \\
\hline & & Aliabad-e Katul & $*$ & - & - & - & - & - & - & $*$ & $*$ & $*$ & - & - & $*$ & - & $*$ & $*$ & - & - & - & - \\
\hline & & Ramian & $*$ & - & - & - & - & - & - & - & - & - & - & - & $*$ & - & - & - & - & - & - & - \\
\hline & & Azad Shahr & $*$ & - & & - & - & - & - & - & - & - & - & - & $*$ & - & - & - & - & - & - & - \\
\hline
\end{tabular}


Tab 3: Ecological characteristics of sandflies in Golestan Province

\begin{tabular}{|c|c|c|c|c|c|c|c|}
\hline \multirow[t]{2}{*}{ Author(s) } & \multirow[t]{2}{*}{ year } & \multirow[t]{2}{*}{ region } & \multicolumn{2}{|c|}{ Dominant species } & \multirow{2}{*}{$\begin{array}{l}\text { Monthly } \\
\text { activity }\end{array}$} & \multirow{2}{*}{$\begin{array}{l}\text { Peak of } \\
\text { activity }\end{array}$} & \multirow{2}{*}{ highlights } \\
\hline & & & indoor & outdoor & & & \\
\hline $\begin{array}{l}\text { Parvizi et } \\
\text { al. }\end{array}$ & 1999 & $\begin{array}{l}\text { Gonbad-e } \\
\text { Kavus }\end{array}$ & - & - & $\begin{array}{l}\text { May - } \\
\text { October }\end{array}$ & August & - \\
\hline $\begin{array}{l}\text { Sofizadeh } \\
\text { et al. }\end{array}$ & 2009 & $\begin{array}{l}\text { Maraveh } \\
\text { Tapeh }\end{array}$ & Ph. papatasi & S.sintoni & $\begin{array}{l}\text { early May - } \\
\text { mid October }\end{array}$ & $\begin{array}{l}\text { Mid June and } \\
\text { September }\end{array}$ & - \\
\hline $\begin{array}{l}\text { Sofizadeh } \\
\text { et al. }\end{array}$ & 2014 & $\begin{array}{l}\text { Aliabad-e } \\
\text { Katul }\end{array}$ & Ph. papatasi & S. sintoni & $\begin{array}{l}\text { mid } \\
\text { May - early } \\
\text { October }\end{array}$ & early August & - \\
\hline $\begin{array}{l}\text { Sofizadeh } \\
\text { et al. }\end{array}$ & 2015 & $\begin{array}{l}\text { Maraveh } \\
\text { Tapeh }\end{array}$ & Ph. papatasi & S. sintoni & - & - & - \\
\hline $\begin{array}{l}\text { Agh- } \\
\text { Atabay et } \\
\text { al. }\end{array}$ & 2016 & $\begin{array}{l}\text { Gonbad-e } \\
\text { Kavus }\end{array}$ & $\begin{array}{l}\text { S.sintoni } \\
\text { Ph. papatasi }\end{array}$ & $\begin{array}{l}\text { S.sintoni } \\
\text { Ph. } \\
\text { papatasi }\end{array}$ & $\begin{array}{l}\text { early May to } \\
\text { mid-October }\end{array}$ & $\begin{array}{l}\text { early July and } \\
\text { mid- } \\
\text { September }\end{array}$ & $\begin{array}{l}\text { The peak of hourly activity of sandflies occurred at night (1900-2000 hrs.). } \\
\text { Population dynamics of } P \text {. papatasi was completely in agreement with calculate } \\
\text { accumulated degree days required for the various stages of their growth }\end{array}$ \\
\hline $\begin{array}{l}\text { Sofizadeh } \\
\text { et al. }\end{array}$ & 2018 & Golestan & - & - & $\begin{array}{l}\text { May- } \\
\text { November }\end{array}$ & - & $\begin{array}{l}\text { The frequency of sand flies in the villages located in northeast of the Golestan } \\
\text { Province (the plateau area, Lower altitude, arid and semi-arid climates, and lower } \\
\text { vegetation cover density) were more than other villages in this province. } \\
\text { There was a significant correlation between the number of collected Ph. papatasi } \\
\text { and incidence of the ZCL }(\mathrm{r}=0.837, \mathrm{P}=0.019) \text {. }\end{array}$ \\
\hline
\end{tabular}




\section{Ecology of reservoirs}

According to studies, L. major is frequently found in R. opimus (25.3\%) and M. libycus (31.8\%) and less commonly found in Meriones persicus and Hemiechinus auritus (17, 25, 37-39). Regarding to the distribution of rodents in Golestan Province, it is necessary to pay attention to a few points:

First, the predominant species is $R$. opimus $(25,26,37-38,40)$ and reported as the main reservoir of the disease, but infection rate of $M$. libycus is higher than $R$. opimus.

Second: Although these rodents exist in most counties of the province, unfortunately, all studies on cutaneous leishmaniasis reservoirs have been concentrated in the counties of Gonbad-e-Kavos and Maraveh Tappeh, but in other parts of the counties, especially in the Kalaleh, Aq Qala and Gomishan Counties, which each year significant reports of leishmaniasis, a study has not been done.

Third: L. turanica has been isolated only from R. opimus $(17,40-41)$ and $L$. closed to gerbili has not been found in reservoirs of the province.

\section{Relationship between the spread of disease and distribution of sand flies and wild rodents}

Recent studies in the province using geographical information systems (GIS) have shown that hotspot areas of cutaneous leishmaniasis and distribution of $R$. opimus completely overlaps with each other particularly in the north and northeastern parts of the province, where in this areas, the presence probability of $P h$. papatasi is more high (42-43). Findings also suggest that the incidence of cutaneous leishmaniasis may be significantly correlated with the number of rodents' active burrows and frequency of $P h$. papatasi (19-20, 29, 43).

In the Golestan Province, the incidence of ZCL seems to be correlated with high temperature, high evaporation rate, low relative humidity, low rainfall rate, low altitude, low normalized difference vegetation index, and low socioeconomic status. Meanwhile, the Max temperature of warmest month $\left({ }^{\circ} \mathrm{C}\right)$, mean temperature of warmest and driest quarter $\left({ }^{\circ} \mathrm{C}\right)$, altitude from the sea level (m) have highest percent contribution distribution of $\mathrm{L}$. major in the Golestan Province (20, 42, 44-47).

Altitude from the sea level, slope, normalized difference vegetation index, mean annual temperature, mean temperature of wettest quarter, and geographic distribution of $\mathrm{R}$. opimus are the most important factors affecting the distribution of $P h$. papatasi species in the province $(43,45-47)$. Also the most important factors affecting with distribution of $R$. opimus are including: Mean temperature of driest quarter $\left({ }^{\circ} \mathrm{C}\right)$, Mean temperature of warmest quarter $\left({ }^{\circ} \mathrm{C}\right)$, Max temperature of warmest month $\left({ }^{\circ} \mathrm{C}\right)$, Altitude from the sea level (m), Normalized difference vegetation index (NDVI) and type of soil.

\section{Treatment}

The efficacy of oral miltefosine for the treatment of cutaneous leishmaniasis caused by $L$. major was identical to that of meglumine antimoniate (Glucantime) (49). The first case of acute urticaria in an infant following systemic glucantime injection to mother was reported from the city of Gonbade Kavus (50).

\section{Control of ZCL}

Unfortunately, not much research has been conducted on the prevention and control of cutaneous leishmaniasis in this province 
In this regard, only one study has been published which reported that proper and extensive control of rodents could significantly reduce the incidence of cutaneous leishmaniasis (Fig. 5) (51).

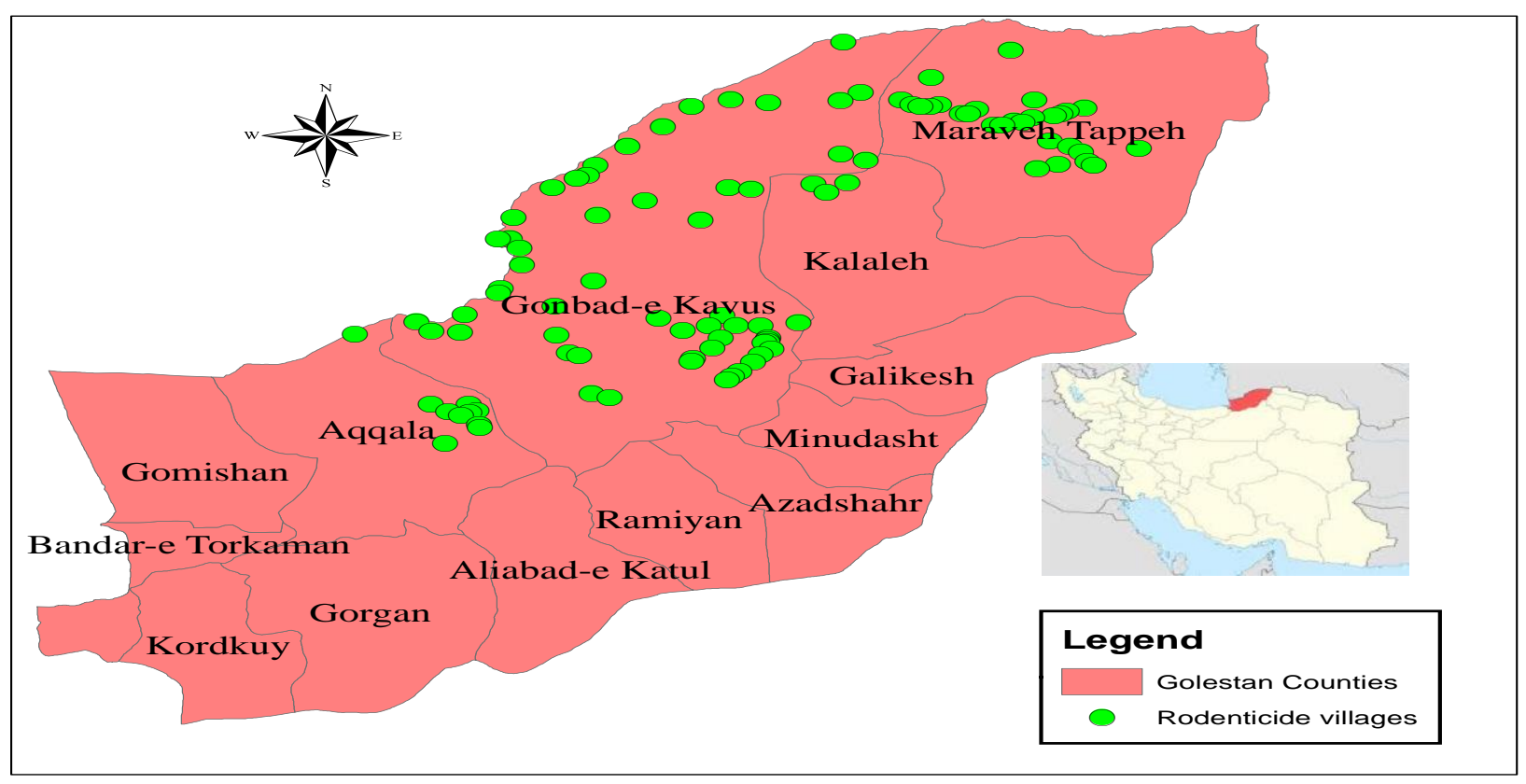

Fig. 5: Villages that have undergone at least one rodenticide operation to decrease the incidence of disease in the past 10 years due to the presence of wild rodents in the village.

\section{Discussion}

The results of various studies in Golestan Province show that the highest number of new cases of cutaneous leishmaniasis and incidence of disease have been reported in Gonbad-e-kavus and Maraveh Tapeh in northeast of Golestan Province and villages in northeast of Gonbad-e-kavus and east of Maraveh Tapeh have been recognized as endemic foci of disease. Therefore, in recent years, control of wild rodents (as cutaneous leishmaniasis reservoir host) has been carried out in these villages to control of cutaneous leishmaniasis (51). Comparison of reported cases of disease over 2013-2018 shows that in 2018 the number of infected cases has increased significantly, and disease were distributed to the central areas of Gonbad-eKavus, Kalaleh and Aq Qala Counties, where have been identified as disease non-endemic areas in recent years. These endemic foci are the habitat of wild rodents due to favorable geographical conditions and soil type, and spreading the disease to non-endemic areas can due to the spread of rodents in these areas or because of infection in endemic areas while traveling endemic areas of the disease. Like other endemic areas of zoonotic cutaneous leishmaniasis, rodents have been also known as the disease reservoir in this province, and $R$. opimus and $M$. libycus are known as the primary and the secondary reservoir, respectively. The similar results are reported in central and northeastern foci of Iran (40, 52-59).

In terms of the distribution of sand flies in Golestan Province, like other parts of the country, Ph. papatasi and S. sintoni are dominant species of sandflies in this province and, $P h$. papatasi has been known as a proven vector of cutaneous leishmaniasis in the province like other endemic areas of zoonotic 
cutaneous leishmaniasis (56-59). Regarding the monthly activity of sand flies, there are two states in this province:

1. In the semi-arid regions of the north and northeast of the province, the sand flies have two peaks of activity in July and at the end of August or early September that these results are similar to the results of studies carried out in most parts of the country and Libya $(7,60,61,62,63)$, also in some areas of Iran, sand flies have two peaks of activity in May and October (64) and in Yazd Province, they have two peaks of activity in the end of April and mid-September (65).

2. the colder and south regions of the Golestan Province, sand flies have one peak of activity in August that is similar to the seasonal activity of the sand flies in the northwest areas of the country (66) . Like most studies conducted in Iran, the abundance of sand flies in Golestan Province in places such as rodents' active burrows and outdoor areas was higher than indoor, which could be due to the favorable temperature and humidity for living the sand flies inside the rodents' active burrows. In addition, with starting night and decreasing temperature, they will start their activity but their peak activity is during 19-20 hours, as similar to other studies in Iran and other countries (67-69). The results of studies conducted in Golestan Province showed that there is a direct relationship between distribution of $P h$. papatasi and $R$. opimus with the distribution of cutaneous leishmaniasis, so that in the north and northeast of Golestan Province where the incidence of the disease is more, distribution of sand flies and wild rodents was also more and their maps are completely matched and similar results have been reported in other studies in Iran (42), these areas are areas with geographic conditions of lowland, low altitude, and semi-arid climate that are conducive to the distribution of sand flies and wild rodents and accordingly, to the distribution of cutaneous leishmaniasis.

\section{Conclusion}

Given the high rate of L. major infection in rodents and the considerable abundance of $P h$. papatasi in the northeast areas, the Golestan Province can be considered an endemic area for zoonotic cutaneous leishmaniasis. Nevertheless, prevention and control of the disease are not sufficiently investigated in this province. Only one article has been published on the impact of rodent control on the incidence of leishmaniasis. Therefore, it is recommended to carry out more studies on the prevention and control of this disease in the Golestan Province, Iran. In addition, as the number of new cases of the disease has increased in recent years and the disease has spread to non-endemic areas, research on the causes of this increase is suggested.

\section{Acknowledgment}

This study is the result of a research project approved by the Infectious Diseases Research Center, Golestan University of Medical Sciences. We would also like to acknowledge the cooperation and assistance from colleagues working at this center.

\section{Ethics approvals and consent to participate}

This study was approved by the ethical committee of Golestan University of Medical Sciences.

\section{Conflict of interest}

There are no conflicts to declare 


\section{References}

1. World Health Organization (WHO). A human rights-based approach to neglected tropical diseases. Geneva: World Health Organization; 2012; [Online] Available from: http://www.who.int/tdr/publications/tdrresearchpublications/human-ights/en/index.html [Accessed on September 3, 2012].

2. Henry JC, Reedijk S, Schallig DFH. Cutaneous Leishmaniasis: Recent Developments in Diagnosis and Management. Am J Clin Dermatol. 2015; 16(2): 99-109. [DOI:10.1007/s40257-0150114-z]

3. Alvar J, Vélez ID, Bern C, Herrero M, Desjeux $\mathrm{P}$, Cano $\mathrm{J}$, et al. Leishmaniasis Worldwide and Global Estimates of Its Incidence. PLoS ONE. 2012; 7(5): $\quad$ e35671 [DOI:10.1371/journal.pone.0035671]

4. Mathers CD, Ezzati M, Lopez AD. Measuring the Burden of Neglected Tropical Diseases: The Global Burden of Disease Framework. PLoS Negl $\begin{array}{llll}\text { Trop } \quad \text { Dis. 2007; } & \text { 1(2): } 114\end{array}$ [DOI:10.1371/journal.pntd.0000114]

5. Akhtari J, Faridnia R, Kalani H, Bastani R, Fakhar M, Rezvan H, Kazemi Beydokhti A. potent in vitro antileishmanial activity of a nanoformulation of cisplatin with carbon nanotubs aginest leishmania major. Journal of Global Antimicrobial Resistance. 2019; 16: 11-16. [DOI:10.1016/j.jgar.2018.09.004]

6. Bailey F, Mondragon-Shem K, Hotez P, RuizPostigo JA, Al-Salem W, Acosta-Serrano A, Molyneux DH. A new perspective on cutaneous leishmaniasis-Implications for global prevalence and burden of disease estimates. PLoS Negl Trop Dis. 2017 Aug; 11(8): e0005739. [DOI:10.1371/journal.pntd.0005739]

7. Karimi A, Hanafi-Bojd AA, Yaghoobi-Ershadi MR, Akhavan AA, Ghezelbash Z. Spatial and temporal distributions of phlebotomine sand flies (Diptera: Psychodidae), vectors of leishmaniasis, in Iran. Acta tropica. 2014; 132: 131-139. [DOI:10.1016/j.actatropica.2014.01.004]

8. Yaghoobi-Ershadi MR. Phlebotomine Sand Flies (Diptera: Psychodidae) in Iran and their Role on Leishmania Transmission. J Arthropod-Borne Dis. 2012; 6(1): 1-17.

9. Mesgarian F, Rahbarian N, Mahmoud Radi M, Hajaran H, Shahbaz S, Mesgarian Z, and et al. Identification of Leishmania species isolated from human cutaneous Leishmaniasis in Gonbad-eQabus city using a PCR method during 20062007. Tehran University Medical Journal. 2010; 68(4): 250-6 (Persian).

10. Tohidi F, Borghaei A. Cutaneous leishmaniasis Parasite Identification via PCR in the Infected Areas in Golestan Province. Knowledge \& Health. 2011; 6(2): 26-31.

11. Tohidi F, Ghaseminejad P, Saedi E, Rostami MDetermination species of cutaneous leishmaniasis by its-PCR in the locations of infection Golestan province in Iran. Tropical Medicine \& International Health. 2011; 16(1): 234-5.

12. Pagheh AS, Fakhar M, Mesgarian F, Gholami $\mathrm{S}$, Badiee F. Detection and Identification of Causative Agent of Cutaneous Leishmaniasis Using Specific PCR. J Mazand Uni Med Sci. 2012; 21(1): 85-92 (Persian).

13. Pagheh AS, Fakhar M, Mesgarian F, RahimiEsboei B, Badiee F. Incidence trend of rural cutaneous leishmaniasis in Gonbad-e-Qabus City (Golestan Province, during 2009-2012. J mazand Uni Med Sci. 2013; 23(104): 27-33 (Persian).

14. Mahmoudzadeh-Niknam H, Ajdary S, RiaziRad F, Mirzadegan E, Rezaeian A, Khaze V, and et al. Molecular epidemiology of cutaneous leishmaniasis and heterogeneity of Leishmania major strains in Iran. Tropical medicine \& international health: TM \& IH. 2012; 17(11): 1335-44.

[DOI:10.1111/j.13653156.2012.03078.x] 
15. Baghaei A, Parvizi P, Amirkhani A, Honarvar MR, Badiei F. Identification of Leishmania using microscopic and molecular methods in suspected patients of Cutaneous Leishmaniasis by targeting ITS-rDNA gene, Golestan province, Iran (200910). Journal of Gorgan University of Medical Sciences. 2012; 14(3): 72-81 (Persian).

16. Bordbar A, Parvizi P. High infection frequency, low diversity of Leishmania major and first detection of Leishmania turanica in human in northern Iran. Acta tropica. 2014; 133: 69-72. [DOI:10.1016/j.actatropica.2014.01.016]

17. Bordbar A, Parvizi P. High density of Leishmania major and rarity of other mammals' Leishmania in zoonotic cutaneous leishmaniasis foci, Iran. Tropical medicine \& international health: TM \& IH. 2014; 19(3): 355-63. [DOI:10.1111/tmi.12258]

18. Hezari F, Niyyati M, Seyyed Tabaei SJ, Mohebali M, Moin Vaziri V, Behniafar H, and et al. Frequency of Cutaneous Leishmaniasis and Species Identification in Suspected Individuals from Golestan Province, Northern Iran in 2014. Iranian journal of public health. 2016; 45(10): 1348-54.

19. Sofizadeh A, Vatandoost H, Rassi Y, HanafiBojd AA, Rafizadeh S. Spatial Analyses of the Relation between Rodent's Active Burrows and Incidence of Zoonotic Cutaneous Leishmaniasis in Golestan Province, Northeastern of Iran. Journal of arthropod-borne diseases. 2016; 10(4): 569-76.

20. Sofizadeh A, Rassi Y, Hanafi-Bojd AA, Shoraka HR, Mesgarian F, Rafizadeh S. Distribution and ecological aspects of sand flies (Diptera: Psychodidae) species in Northeastern Iran. Asian Pacific Journal of Tropical Medicine. 2018; 11(9): 526. [DOI:10.4103/19957645.242309]

21. Sofizadeh A, Rassi Y, Abbai M, Oshaghi MA, Salahi R, Rafizadeh S, Mohebali M. Ecological characters of Leishmaniasis vectors in Kalaleh district. Golestan Province, Iran. Gorgan Uni Med Sci. 2007; 11(3): 81-5 (Persian).

22. Sofizadeh A, Faragi Far AA, Cherabi M, Badiei F, Cherabin M, Sarli J, Yapang Gharavi M, Mehravaran A. Cutaneous leishmaniasis in Gonbad Kavoos, North of Iran (2009-11): an epidemiological. J Gorgan Uni Med Sci. 2013; 14(4): 100-106 (Persian).

23. Cherabin M, Sofizadeh A, Palideh AR, Yapang Gharavi AH, Yapang Gharavi M. Epidemiological characteristics of Cautaneous Leishmaniasis in Maraveh tapeh district, Golestan province during 2006-2010. Journal of Zabol University of medical sciences and health services. 2012; 4(1): 19-27 (Persian).

24. Sofizadeh A, Ghorbani M, Gorganli Davaji A, Gharemeshk Gharavi A. Epidemiological status of cutaneous leishmaniasis and ecological characteristics of sandflies in Maraveh-Tapeh county, Golestan province, 2011-2012, Iran. Qom Univ Med Sci J. 2015; 9(6): 53-65 (Persian).

25. Rassi Y, Sofizadeh A, Abai MR, Oshaghi MA, Rafizadeh S, Mohebail M. Molecular Detection of Leishmania major in the Vectors and Reservoir Hosts of Cutaneous Leishmaniasis in Kalaleh District, Golestan Province, Iran. Journal of Arthropod- Borne Diseases. 2008; 2(2): 21-27.

26. Agh-Atabay MD, Sofizadeh A, Ozbaki GM, Malaki-Ravasan N, Ghanbari MR, Mozafari O Ecoepidemiological characteristics of a hypoendemic focus of zoonotic cutaneous leishmaniasis in north Iran (southeast of Caspian Sea). Journal of vector borne diseases. 2016; 53(3): 248-56.

27. Parvizi P, Javadian E., Rassi Y, Amirkhani A. A Study on Vector and Reservoir Host of Cutaneous Leishmaniasis in Turkamansahra, Golestan Province, North-East of Iran. Pathobiology Reaearch. 1999; 3-4 (2): 125-130 (persian)

28. Bagheri A, Sofizadeh A, Ghezel AH, Ghanbari MR, Fadaei E, Yapang Gharavi M, and et al. Ecological characteristics of sand flies in 
Golestan province, Iran (2011). Journal of Gorgan University of Medical Sciences. 2014; 15(4): 84-9 (Persian).

29. Sofizadeh A, Rassi Y, Vatandoost H, HanafiBojd AA, Mollalo A, Rafizadeh S. Predicting the distribution of Phlebotomus papatasi (diptera: psychodidae), the primary vector of zoonotic cutaneous leishmaniasis, in Golestan Province of Iran Using ecological niche modeling: comparison of MaxEnt and GARP models. Journal of medical entomology. 2016; 54(2): 312-20. [DOI:10.1093/jme/tjw178]

30. Roshanghalb M, Parvizi P. Isolating and Determining Leishmania major and Leishmania turanica in Phlebotomus papatasi in Golestan Province. J Mazand Uni Med Sci. 2012; 21(1): 74-83 (Persian).

31. Parvizi P, Ready P. Nested PCRs and sequencing of nuclear ITS-rDNA fragments detect three Leishmania species of gerbils in sandflies from Iranian foci of zoonotic cutaneous leishmaniasis. Tropical Medicine \& International Health. 2008; 13(9): 1159-71. [DOI:10.1111/j.1365-3156.2008.02121.x]

32. Sharbatkhori M, Spotin A, Taherkhani H, Roshanghalb M, Parvizi P. Molecular variation in Leishmania parasites from sandflies species of a zoonotic cutaneous leishmaniasis in northeast of Iran. Journal of vector borne diseases. 2014; 51(1): 16-21.

33. Yaghoobi-Ershadi MR, Javadian E. Epidemiological study of reservoir hosts in an endemic area of zoonotic cutaneous leishmaniasis in Iran. Bulletin of the World Health Organization. 1996; 74(6): 587-90.

34. Azizi K, Rassi Y, Javadian E, Motazedian M, Rafizadeh S, Yaghoobi Ershadi M. Phlebotomus (Paraphlebotomus) alexandri: a probable vector of Leishmania infantum in Iran. Annals of Tropical Medicine \& Parasitology. 2006; 100(1): 63-8. [DOI: 10.1179/136485906X78454]

35. Zahraei-Ramazani A, Kumar D, Mirhendi H, Sundar S, Mishra R, Moin-Vaziri V.
Morphological and genotypic variations among the species of the subgenus Adlerius (Diptera: Psychodidae, Phlebotomus) in Iran. Journal of arthropod-borne diseases. 2015; 9(1): 84.

36. Seyedi-Rashti M, Agh-Ataby MD, Mohebali M. Natural promastigote infection of Sergentomyia sintoni, its seasonal variation and reservoir host in Turkemen-Sahara, Iran. Iranian J Public Health. 1994; 23(1): 41-50.

37. Parvizi P, Hedayati M. Leishmania infections in rodents, reservoir hosts of zoonotic cutaneous leishmaniasis in Turkemen Sahara. J. Guilan Uni. Med. Sci. 2010; 18(72): 30-8 (Persian).

38. Mirzaei A, Rouhani S, Taherkhani H, Farahmand M, Kazemi B, Hedayati M. Isolation and detection of Leishmania species among naturally infected Rhombomis opimus, a reservoir host of zoonotic cutaneous leishmaniasis in Turkemen Sahara, North East of Iran. Experimental parasitology. 2011; 129(4): 375-80. [DOI:10.1016/j.exppara.2011.08.020]

39. Rouhani S, Mirzaei A, Spotin A, Parvizi P. Novel identification of Leishmania major in Hemiechinus auritus and molecular detection of this parasite in Meriones libycus from an important foci of zoonotic cutaneous leishmaniasis in Iran. Journal of infection and public health. 2014; 7(3): 210-7. [DOI:10.1016/j.jiph.2013.12.002]

40. Akhoundi M, Mohebali M, Asadi M, Mahmodi MR, Amraei K, Mirzaei A. Molecular characterization of Leishmania spp. in reservoir hosts in endemic foci of zoonotic cutaneous leishmaniasis in Iran. Folia parasitological. 2013; 60(3): 218-24. [DOI:10.14411/fp.2013.024]

41. Mirzaei A, Schweynoch C, Rouhani S, Parvizi P, Schonian G. Diversity of Leishmania species and of strains of Leishmania major isolated from desert rodents in different foci of cutaneous leishmaniasis in Iran. Transactions of the Royal Society of Tropical Medicine and Hygiene. 2014; 108(8): 502-12. [DOI:10.1093/trstmh/tru085] 
42. Sofizadeh A, Hanafi-Bojd AA, Shoraka HR. Modeling spatial distribution of Rhombomys opimus as the main reservoir host of zoonotic cutaneous leishmaniasis in northeastern Iran. J vector Borne Dis. 2018; 55: 184- 191. [DOI:10.4103/0972-9062.256565]

43. Sofizadeh A, Rassi Y, Vatandoost H, HanafiBojd AA, Mollalo A, Rafizadeh S. Predicting the Distribution of Phlebotomus papatasi (Diptera: Psychodidae), the Primary Vector of Zoonotic Cutaneous Leishmaniasis, in Golestan Province of Iran Using Ecological Niche Modeling: Comparison of MaxEnt and GARP Models. Journal of Medical Entomology. 2017; 54(2): 312-20. [DOI:10.1093/jme/tjw178]

44. Shirzadi MR, Mollalo A, Yaghoobi-Ershadi MR. Dynamic Relations between Incidence of Zoonotic Cutaneous Leishmaniasis and Climatic Factors in Golestan Province, Iran. Journal of arthropod-borne diseases. 2015; 9(2): 148-60.

45. Mollalo A, Sadeghian A, Israel GD, Rashidi P, Sofizadeh A, Glass GE. Machine learning approaches in GIS-based ecological modeling of the sand fly Phlebotomus papatasi, a vector of zoonotic cutaneous leishmaniasis in Golestan Province, Iran. Acta tropica. 2018; 188: 187-94. [DOI:10.1016/j.actatropica.2018.09.004]

46. Mollalo A, Khodabandehloo E. Zoonotic cutaneous leishmaniasis in northeastern Iran: A GIS-based spatio-temporal multi-criteria decisionmaking approach. Epidemiology \& Infection. 2016; 144(10): 2217-29. [DOI:10.1017/S0950268816000224]

47. Ahmadpour M, Varasteh Moradi H, Rezaei HR, Oshaghi MA, Hosseinzadeh Colagar A. Modeling of the Geographical Distribution Effects of Great Gerbil (Rhombomis opimus) on Distribution of Sandfly Phlebotomus papatasi in Golestan Province. Animal Environment. 2017; 9(4): 73-80 (Persian).

48. Mollalo A, Alimohammadi A, Shirzadi M, Malek M. Geographic information system-based analysis of the spatial and spatio-temporal distribution of zoonotic cutaneous leishmaniasis in Golestan Province, north-east of Iran. Zoonoses and public health. 2015; 62(1): 18-28. [DOI:10.1111/zph.12109]

49. Mohebali M, Fotouhi A, Hooshmand B, Zarei Z, Akhoundi B, Rahnema A, Razaghian AR, Kabir MJ, Nadim A. Comparison of miltefosine and meglumine antimoniate for the treatment of zoonotic cutaneous leishmaniasis (ZCL) by a randomized clinical trial in Iran. Acta Tropica. 2007; 103: 33-40. [DOI:10.1016/j.actatropica.2007.05.005]

50. Mozafari O, Shorofi SA, Yousefi SS. First Report on Infant Acute Urticaria after Mother's Parenteral Use of Meglumine Antimoniate (Glucantime): A Case Report. Iranian journal of public health. 2016; 45(9): 1217.

51. Kalteh EA, Sofizadeh A, Yapng Gharavi AH, Ozbaki GM, Kamalinia HR, Bagheri A, Sarli J Effect of wild rodents control in reduction of zoonotic cutaneous leishmaniasis in Golestan Province, north of Iran (2016). J Gorgan Univ Med Sci. 2019; 21(1): 94-100 (Persian).

52. Doroodgar A, Sadr F, Razavi MR, Doroodgar M, Asmar M, Doroodgar M. A new focus of zoonotic cutaneous leishmaniasis in Isfahan Province, Central Iran. Asian Pac J Trop Dis. 2015; 5(1): S54-S58. [DOI:10.1016/S22221808(15)60857-X]

53. Yaghoobi-Ershadi MR, Marvi-Moghadam N, Jafari R, Akhavan AA, Solimani H, ZahraiRamazani AR, Arandian MH, Dehghan-Dehnavi AR. Some Epidemiological Aspects of Cutaneous Leishmaniasis in a New Focus, Central Iran. Dermatology Research and Practice. 2015; Article ID 286408, 5 pages. [DOI:10.1155/2015/286408]

54. Rassi Y, Oshaghi MA, Mohammadi Azani S, Abaie MR, Rafizadeh S, Mohebali M, Mohtarami F, Zeinali MK. Molecular Detection of Leishmania Infection Due to Leishmania major and Leishmania turanica in the Vectors and Reservoir Host in Iran. Vector-Borne and 
Zoonotic Diseases. 2011; 11 (2): 145-150. [DOI:10.1089/vbz.2009.0167]

55. Mohebali M, Javadian E, Yaghoobi-Ershadi MR, Akhavan AA, Hajjaran H, Abaei MR. Characterization of Leishmania infection in rodents from endemic areas of the Islamic Republic of Iran. Eastern Mediterranean Health Journal. 2004; 10(4/5): 591-599.

56. nAbai MA, Rassi Y, Imamian H, Fateh M, Mohebali M, Rafizadeh S. and et al., PCR based on identification of vectors of zoonotic cutaneous Leishmaniasis in Shahrood District, Central of Iran. Pak J Biol Sci. 2007; 10(12): 2061-5. [DOI:10.3923/pjbs.2007.2061.2065]

57. Abdoli H, Hejazi SH, Akhavan AA, ZahraeiRamazani AR, Yaghoobi-Ershadi MR, JalaliZand AR, and et al., Some Ecological Aspects of Phlebotomine Sand Flies in an Endemic Focus of Cutaneous Leishmaniasis in Iran. Iranian Journal of Arthropod-Borne Diseases. 2007; 1(2), 34-9.

58. Yaghoobi-Ershadi MR, Jafari R, Zarean M, Akhavan A, Mohenali M. Ecological study of phlebotomines in an endemic leishmaniasis in Isfahan city. Journal of Shahid Sadoughi University of Medical Sciences. 2002; 9(4), 42-8 (in Persian).

59. Yaghoobi-Ershadi MR, Jafari R, Hanafi-Bojd AA. A new epidemic focus of zoonotic cutaneous leishmaniasis in central Iran. Annals of Saudi Medicine. 2004; 24(2): 98-101. [DOI:10.5144/0256-4947.2004.98]

60. Yaghoobi-Ershadi MR, Akhavan AA, Zahraei-Ramazani AV, Abai MR, Ebrahimi B, Vafaei-Nezhad R, and et al. Epidemiological study in a new focus of cutaneous leishmaniasis in the Islamic Republic of Iran. East Mediterr Health J. 2003; 9(4): 816-826.

61. Azizi K, Parvinjahromi H, MoemenbellahFard MD, Sarkari B, Fakoorziba MR, Faunal Distribution and Seasonal Bio-Ecology of Naturally Infected Sand Flies in a New Endemic Zoonotic Cutaneous Leishmaniasis Focus of
Southern Iran. Journal of Arthropod-Borne Diseases. 2016; 10(4): 560-568.

62. Kassiri H, Javadian E, Sharififard M. monthly activity of Phlebotominae sand flies in SistanBaluchistan Province, Southeast Iran. J Insect Science. $\quad 2013 ; \quad 13(1)$ : $1-7$. [DOI:10.1673/031.013.15301]

63. Dokhan MR, Kenawy MA, Doha SA, ElHosary SS, Shaibi T, Annajar BB. Entomological studies of phlebotomine sand flies (Diptera: Psychodidae) in relation to cutaneous leishmaniasis transmission in Al Rabta, North West of Libya. Acta Tropica. 2016; 154: 95-101. [DOI:10.1016/j.actatropica.2015.11.004]

64. Azizi K, Abedi F, Moemenbellah-Fard MD. Identification and frequency distribution of Leishmania (L.) major infections in sand flies from a new endemic ZCL focus in southeast Iran. Parasitology Research. 2012; 11(4): 1821-1826. [DOI:10.1007/s00436-012-3029-0]

65. Mirhoseini M, Salehzadeh A, Ramazan Jamaat S, Zahirnia AH, Rahmanzadeh N. Distribution and Seasonal Activity of Phlebotominae Sand Flies in Yazd and Its Outskirts, Center of Iran. Hindawi the Scientific World J. 2017; 1486845: 1-5. [DOI:10.1155/2017/1486845]

66. Hazratian T, Vatandoost H, Oshaghi MA, Yaghoobi-Ershadi MR. Diversity of sand flies (Diptera: Psychodidae) in the endemic focus of visceral leishmaniasis in Azar Shahr District, East Azarbaijan Province, North West of Iran. J arthropod-Borne Diseases. 2016; 10(3): 330-336.

67. Nadim. A. seasonal changes of the hourly activity of sandflies of Rhombomys burrows in Isfahan, Iran. Trop.Geogr Med. 1972; 24: 382384.

68. El said, s; Beier J.C; El Sawaf B.M; Doha S. and at al. sandflies associated with visceral leishmaniasis in EL Agamy, Alexanderia governorat Egy II. Fieid Behavior. J . MED.Entomology; $\quad 1986 ; \quad 23: 609-615$ [DOI:10.1093/jmedent/23.6.609] 
69. Feliciageli MD. Hourly activity of Lutzomyia ovallesi and L. gomezi (Diptera: psychodidae), vectors of cutaneous leishmaniasis in north central
Venezuela. Med Entomol. 1997; 34(2): 110-5. [DOI:10.1093/jmedent/34.2.110]

\section{How to cite:}

Mozafari M, Sofizadeh A, Shoraka H.R, Namroodi J, Kalteh E.A. Eco-Epidemiology of Cutaneous Leishmaniasis in Golestan Province, Northeastern Iran: A Systematic Review. Jorjani Biomedicine Journal. 2020; 8(1): 60-78. 